\title{
Influence of Education and Occupation on the Incidence of Alzheimer's Disease
}

\author{
Yaakov Stern, PhD; Barry Gurland, MD; Thomas K. Tatemichi, MD; Ming Xin Tang, PhD; \\ David Wilder, PhD; Richard Mayeux, MD
}

Objective.-Several cross-sectional studies have found an association between Alzheimer's disease (AD) and limited educational experience. It has been difficult to establish whether educational experience is a risk factor for AD because educational attainment can influence performance on diagnostic tests. This study was designed to determine whether limited educational level and occupational attainment are risk factors for incident dementia.

Design.-Cohort incidence study.

Setting.-General community.

Participants.-A total of 593 nondemented individuals aged 60 years or older who were listed in a registry of individuals at risk for dementia in North Manhattan, NY, were identified and followed up.

Interventions.-We reexamined subjects 1 to 4 years later with the identical standardized neurological and neuropsychological measures.

Main Outcome Measure.-Incident dementia.

Results.-We used Cox proportional hazards models, adjusting for age and gender, to estimate the relative risk (RR) of incident dementia associated with low educational and occupational attainment. Of the 593 subjects, 106 became demented; all but five of these met research criteria for $A D$. The risk of dementia was increased in subjects with either low education (RR, 2.02; 95\% confidence interval [Cl], 1.33 to 3.06 ) or low lifetime occupational attainment (RR, 2.25; $95 \% \mathrm{Cl}$, 1.32 to 3.84). Risk was greatest for subjects with both low education and low lifetime occupational attainment (RR, 2.87; $95 \% \mathrm{Cl}, 1.32$ to 3.84 ).

Conclusions.-The data suggest that increased educational and occupational attainment may reduce the risk of incident $A D$, either by decreasing ease of clinical detection of $A D$ or by imparting a reserve that delays the onset of clinical manifestations.

(JAMA. 1994;271:1004-1010)

THE PREVALENCE of Alzheimer's disease (AD) seems to be higher in individuals with fewer years of education. ${ }^{1-6}$ There are several possible ex-

From the Departments of Neurology (Drs Stern Tatemichi, Tang, and Mayeux) and Psychiatry (Drs Stern and Mayeux), Columbia University College of Physicians and Surgeons; Gertrude H. Sergievsky Center (Drs Stern, Gurland, Tatemichi, Tang, Wilder, and Mayeux); and Center for Geriatrics and Gerontology (Drs Gurland and Wilder), New York, NY.

Reprint requests to Sergievsky Center, 630 W 168th St, New York, NY 10032 (Dr Stern). planations for these findings. Having a lower educational level might in some way cause AD or influence a causal factor. ${ }^{7}$ Education may also provide protection or reserve against the clinical manifestation of $\mathrm{AD},,^{8-11}$ as supported by two studies of regional cerebral blood flow in $A D \cdot{ }^{12,13}$ However, individuals with lower educational attainment may simply perform worse on the psychometric tests used to diagnose dementia, while those with higher education perform better. ${ }^{14}$ In one study there was no association between education and the risk of dementia, ${ }^{15}$ but the subjects were predominantly well-educated individuals who had reached medical attention.

The present analyses were designed to clarify the role of education in a prospective study of incident dementia. Because all subjects originally had the same diagnostic evaluation and were judged to be nondemented, the diagnosis of incident dementia at follow-up necessarily implies major decline from initial performance and minimizes the chance of misdiagnosing a nondemented individual who could never have passed the diagnostic tests.

We hypothesized that education contributes to the reserve against dementia by supplying a set of skills or repertoires that allow an individual to cope longer before the clinical manifestations of $\mathrm{AD}$ emerge. The relatively brief period of life spent in school, however, might not be as important as the individual's lifetime occupation. To that end, we evaluated both educational and occupational experience as antecedent factors for incident dementia.

\section{METHODS}

\section{Subjects}

Data were obtained from subjects participating in a study of dementia in individuals aged 60 to 99 years who resided in the Washington Heights and Inwood communities of New York City. As part of that study, we developed a registry of unaffected subjects. Sources of subjects included in the present analyses were as follows: regional medical facilities (inpatient and outpatient services and private practitioners in the community) (14.7\%); nursing homes serving local residents (2.7\%); a state agency list of home care recipients (21.7\%); and senior centers and 
housing $(4.6 \%)$. Some subjects volunteered or were self-referred (19.5\%), and some spouses of individuals identified as cases were asked to participate as controls $(6.8 \%)$. In addition, some community residents were recruited based on random sampling of a commercial list and one obtained from the Health Care Financing Agency (30\%). Overall, the refusal rate was approximately $30 \%$, with the largest percentage of referrals coming from individuals contacted through the random sampling of lists. The Columbia University institutional review board reviewed and approved this project. All subjects provided written informed consent.

The study design required that subjects be evaluated yearly. Subjects included in the current analyses met the following criteria: (1) They were nondemented at the baseline diagnostic evaluation (described below); (2) they had not had an acute stroke or Parkinson's disease in the year prior to their initial visit; and (3) they were seen for at least one follow-up evaluation. All subjects were at least 60 years of age at baseline. While this study used individuals from the registry who were not demented, many were identified from medical settings or were self-referred and may be considered at higher than usual risk for becoming demented.

\section{Diagnostic Evaluation}

All subjects had the same standardized evaluation at each study visit. The neuropsychological battery ${ }^{16}$ took approximately 1 hour to complete and contained tests of memory (short- and long-term verbal ${ }^{17}$ and nonverbal ${ }^{18}$ ); orientation; abstract reasoning (verbal ${ }^{19}$ and nonverbal ${ }^{20}$ ); language (naming, ${ }^{21}$ verbal fluency, ${ }^{22,23}$ comprehension ${ }^{23}$, and repetition ${ }^{23}$ ); and construction (copying ${ }^{24}$ and matching ${ }^{18}$ ). Test scores were evaluated using a fixed paradigm ${ }^{16}$ : criterion scores were applied to each test score, and subjects performing below these scores on two of the three aspects of memory testing as well as two other areas (orientation, language, abstract reasoning, or construction) were considered to have sufficient cognitive deficit to meet criteria for dementia.

A physician elicited each subject's medical and neurological history and conducted a standardized physical and neurological examination. All ancillary information, including medical charts and reports of computed tomographic (CT) or magnetic resonance imaging (MRI) scans, if available, was included in the evaluation. The presence of a history or signs or symptoms of stroke was noted, as well as the presence of diabetes or hypertension. Prescribed medications were reviewed and recorded. Separate from the neuropsychological testing, the physician administered the short version of the Blessed Memory Information and Concentration Test ${ }^{25}$ as well as assessments of functional capacity or activities of daily living, including the Blessed Dementia Rating Scale (part I, sections $A$ and $B)^{26}$ and the Schwab and England Activities of Daily Living Scale. $^{27}$

Trained interviewers administered a set of screening items for depression, psychosis, and alcohol abuse (Structured Clinical Interview for $D S M-I I I-R$ Diagnosis [SCID] screen ${ }^{28}$ ), as well as the Hamilton Depression Rating Scale. ${ }^{29,30}$ Smoking history was also obtained.

Evaluations were conducted in either English or Spanish, based on the subjects' primary language and their opinion of which language would yield better performance.

Information from all of these evaluations was presented at a diagnostic conference of physicians and neuropsychologists, and a consensus diagnosis was made for the presence or absence of dementia. The diagnosis of dementia was based on the criteria of the Diagnostic and Statistical Manual of Mental Disorders, Revised Third Edition (DSM-III-R), ${ }^{31}$ and required evidence of cognitive deficit, based on the neuropsychological scores, as well as evidence of impairment in social or occupational function, based on the formal functional assessments, elicited history, or both.

When dementia was diagnosed, all available data were evaluated to determine the type of dementia present. For the diagnosis of probable or possible $\mathrm{AD}$, we used the criteria of the National Institute of Neurological and Communicative Disorders and Stroke-Alzheimer's Disease and Related Disorders Association. ${ }^{32}$ If there was no evidence of any concomitant condition that could contribute to the observed dementia, a diagnosis of probable $\mathrm{AD}$ was made. If subjects had clinical evidence or a history of stroke or had a lesion noted on MRI, we distinguished between the diagnoses of possible AD with concomitant stroke and multi-infarct (or strokerelated) dementia. We diagnosed multiinfarct dementia only when there appeared to be a clear temporal relationship between vascular events and the onset of dementia. We operationally defined this association as onset of dementia within 3 months of the stroke. For example, if a subject who was not demented at the initial visit had a small subcortical lesion visible on a scan that predated the initial visit, subsequent incident dementia would be diagnosed as possible $\mathrm{AD}$ with concomitant stroke.
On the other hand, a subject who was not demented at the initial visit but subsequently suffered a stroke and then became demented would be diagnosed with a stroke-related dementia. For the purposes of the present analyses, this differential diagnosis was aided by the facts that no subject was demented at the initial visit and that we excluded subjects who had had an acute stroke prior to the initial visit.

A modified Clinical Dementia Rating $(\mathrm{CDR})^{33}$ was assigned to each subject. For nondemented individuals, the CDR rating was either 0 , not demented, or 0.5 , borderline dementia. The latter category was assigned to subjects who did not have sufficient cognitive deficit to meet criteria for dementia according to the fixed paradigm used to evaluate neuropsychological test scores. However, their test performance fell below many of the paradigm's criterion scores and they had evidence of mild functional problems. Demented patients were assigned CDR scores of 1 or more, based on the published criteria.

Neurologists who examined the subjects were also members of the diagnostic conference panel. The neuropsychological testers did not directly participate in the diagnostic conference, however. The members of the diagnostic conference were usually aware of the educational but not the occupational attainment of subjects. However, this did not influence diagnosis of dementia because the primary dementia criterion, cognitive deficit, was based on a fixed neuropsychological test score paradigm. In addition, subjects were evaluated as part of a larger study that was unrelated to the present hypotheses.

\section{Occupation}

At the initial visit, the subject's primary occupation was recorded and classified based on the following US census categories: student, housewife, unskilled/ semiskilled, skilled trade or craft, clerical/office worker, manager business/government, and professional/technical. A housewife who had been employed outside the home for a significant period of her adult life (ie, $>10$ years) was classified according to that occupation.

\section{Statistical Analysis}

We used Cox proportional hazards models $^{34}$ to assess relative risk (RR) of incident dementia associated with education and occupation. The subject's age was used as the reference point for the relative timing of each diagnostic evaluation. To adjust for possible cohort effects, however, follow-up Cox analyses were recalculated stratified by age (di- 
Table 1.-Comparison of Demographics in Subjects Who Were and Were Not Followed Up After Their Initial Evaluation

\begin{tabular}{lcc}
\hline \multicolumn{1}{c}{ Demographic } & Follow-up & $\begin{array}{c}\text { Baseline } \\
\text { Only }\end{array}$ \\
\hline No. of subjects & 593 & 210 \\
Age, y, mean \pm SE & $74.0 \pm 7.6$ & $74.2 \pm 8.3$ \\
Gender, \% female & 72.9 & 68.6 \\
Education, y, mean \pm SE & $9.6 \pm 4.7$ & $8.8 \pm 5.0^{*}$ \\
Education, high/low & $329 / 264$ & $102 / 108$ \\
Occupation, high/low & $201 / 328$ & $59 / 124$ \\
\end{tabular}

*t test, $P<.05$

Table 2.-Demographics in Subjects Who Did and Did Not Become Demented

\begin{tabular}{lcc}
\hline \multicolumn{1}{c}{ Demographic } & $\begin{array}{c}\text { No Incident } \\
\text { Dementia }\end{array}$ & $\begin{array}{c}\text { Incident } \\
\text { Dementia }\end{array}$ \\
\hline No. of subjects & 487 & 106 \\
Age, y, mean \pm SE & $72.9 \pm 7.0$ & $79.0 \pm 8.3$ \\
Gender, \% female & 72.7 & 73.6 \\
Education, y, mean \pm SE & $10.1 \pm 4.5$ & $7.1 \pm 4.7$ \\
Education, high/low & $292 / 195$ & $37 / 69$ \\
Occupation, high/low & $184 / 256$ & $17 / 71$ \\
Length of follow-up, y & & \\
$\geq 1$ & 487 & 106 \\
$\geq 2$ & 350 & 53 \\
$\geq 3$ & 166 & 16 \\
4 & 41 & 4 \\
\hline
\end{tabular}

chotomized based on the median age to $\leq 72$ years and $>72$ years). All analyses included gender as a covariate. Initial analyses treated education as a continuous variable. To aid in the interpretation of $R R$ values and to investigate the relative contributions of education and occupation, educational level was dichotomized into low ( $<8$ years) and high ( $\geq 8$ years). For the analysis of occupation, we initially omitted the 51 subjects who were classified exclusively as housewives and the eight whose occupation was unknown, since these classifications could not be fit directly into our social class hierarchies. The remaining classifications were grouped into low (unskilled/semiskilled, skilled trade or craft, and clerical/office worker) and high (manager business/government and professional/technical) occupational levels. Follow-up analyses treated the housewives as a third occupational group.

Initially, the RRs associated with low education and low occupation were analyzed separately. To evaluate potential interactions of risk associated with education and occupation, these variables were then included in the same Cox model. In addition, subjects were divided into four groups: low education and low occupation, high education and low occupation, low education and high occupation, and high education and high occupation. The RR of dementia was calculated using the high-education and high-occupation group as the reference group.

Life-table techniques ${ }^{35}$ were also used to calculate cumulative incidence of dementia to a series of ages in the various

Table 3.-Demographics in the Educational and Occupational Groups

\begin{tabular}{lcccc}
\multicolumn{1}{c}{ Demographic } & $\begin{array}{c}\text { Low } \\
\text { Education }\end{array}$ & $\begin{array}{c}\text { High } \\
\text { Education }\end{array}$ & $\begin{array}{c}\text { Low } \\
\text { Occupation }\end{array}$ & $\begin{array}{c}\text { High } \\
\text { Occupation }\end{array}$ \\
\hline No. of subjects & 264 & 329 & 327 & 201 \\
\hline Age, y, mean \pm SE & $75.1 \pm 7.6$ & $73.2 \pm 7.6$ & $74.0 \pm 7.7$ & $73.3 \pm 7.5$ \\
\hline Gender, \% female & 75.4 & 70.8 & 69.1 & 71.1 \\
\hline Education, y, mean $\pm S E$ & $5.3 \pm 2.6$ & $13.0 \pm 2.8$ & $7.9 \pm 3.6$ & $13.5 \pm 3.7$ \\
\hline Education, high/low & $\ldots$ & $\ldots$ & $130 / 197$ & $182 / 19$ \\
\hline Occupation, high/low & $19 / 197$ & $182 / 130$ & $\ldots$ & $\ldots$ \\
\hline Length of follow-up, y & 264 & 329 & 327 & 201 \\
\hline$\geq 1$ & 185 & 237 & 219 & 158 \\
\hline$\geq 2$ & 60 & 114 & 97 & 79 \\
\hline$\geq 3$ & 12 & 36 & 19 & 26
\end{tabular}

study groups. These calculations were uncorrected for other covariates.

We used $x^{2}$ analyses to examine the concordance of educational and occupational attainment and to compare frequencies of potentially relevant covariates in the educational and occupational groups. Repeated measures analyses of variance were used to examine change in measures of function over time.

\section{RESULTS}

\section{Subject Accrual and Follow-up}

At least one follow-up evaluation was performed on 593 individuals who were not demented at the initial evaluation. For subjects with more than one followup evaluation, we used the last followup period if the subject remained nondemented. For incident dementia cases, we used the first follow-up visit at which dementia was documented.

We compared demographics of subjects recruited through different mechanisms. Distribution of age, gender, education, and occupation was similar across recruitment techniques.

A total of 210 additional subjects were not demented at the initial evaluation and were not followed up. For $25(12 \%)$ of these 210 subjects, less than 1 year had elapsed since the initial evaluation. Reasons for failure to reevaluate the others were death (41 [19.5\%]), unavailability for follow-up or relocation ( 65 [31\%]), and refusal (79 [37.5\%]). Mean age and distribution of gender, education (high vs low), and occupation did not differ significantly in the groups that were and were not followed up (Table 1). Mean education was approximately 1 year lower in the group that was not followed up $(P<.05)$.

\section{Incident Dementia}

Of the $\mathbf{5 9 3}$ reevaluated subjects, $\mathbf{1 0 6}$ were diagnosed with dementia at followup, an incidence rate of 86.7 per 1000 person-years. All but nine met criteria for probable (66 subjects) or possible (31 subjects) AD. All subjects were retained in the analyses regardless of de- mentia subtype. Demographics of subjects who did and did not become demented are presented in Table 2 . Table 3 presents demographics of subjects in the high and low educational and occupational groups.

When years of education was treated as a continuous variable in a Cox analysis, more years of education was associated with a reduced risk of dementia (RR, $0.92 ; 95 \%$ confidence interval [CI], 0.88 to 0.95 ). When education was stratified into high and low educational groups and compared by Cox analyses, lower educational level was associated with a higher RR of dementia; similarly, lower occupational attainment was associated with a higher risk of dementia (Table 4).

Educational level and occupational attainment were strongly related $\left(\chi^{2}, 131\right.$; $P<.001)$. However, these two areas of life experience were sometimes incongruent. A Cox model simultaneously considered the effects and interaction of education and occupation. The interaction effect was significant ( RR, 2.17; 95\% CI, 1.40 to 3.36). To further explore this interaction, subjects were assigned to one of four education/occupation groups and risk of dementia based on group membership was evaluated in a Cox analysis (Table 4). Risk of dementia was highest in the low-education/low-occupation group. Based on the criteria described by Rothman, ${ }^{36}$ the effects of education and occupation meet criteria for interaction on an additive or multiplicative scale, suggesting a synergistic effect of education and occupation.

The cumulative incidence rates of dementia were higher in the low-education and low-occupation groups. A similar analysis for the four education/occupation groups also showed the highest cumulative incidence rates in the low-education/low-occupation group (Table 5).

\section{Supplementary Analyses}

Alternate Occupational Ratings.Our primary analyses for occupation excluded housewives, because we could not readily include them in our strati- 
Table 4.-Summary of Cox Proportional Hazard Models for Predicting Incident Dementia by Education and Occupation, Controlling for Age, Stratified as Old and Young, and for Gender

\begin{tabular}{lcccc} 
Group & $\begin{array}{c}\text { Total No. of } \\
\text { Subjects }\end{array}$ & $\begin{array}{c}\text { No. of Incident } \\
\text { Dementia Cases }\end{array}$ & $\begin{array}{c}\text { Relative } \\
\text { Risk }\end{array}$ & $\begin{array}{c}\text { 95\% Confldence } \\
\text { interval }\end{array}$ \\
\hline $\begin{array}{l}\text { Education } \\
\text { Low }\end{array}$ & 264 & 69 & 2.02 & $1.33-3.06$ \\
\hline $\begin{array}{l}\text { High } \\
\begin{array}{l}\text { Occupation } \\
\text { Low }\end{array}\end{array}$ & 329 & 37 & 1 & Reference \\
\hline High & 327 & 71 & 2.25 & $1.32-3.84$ \\
\hline $\begin{array}{l}\text { Education/occupation } \\
\text { Low/low }\end{array}$ & 201 & 17 & 1 & Reference \\
\hline $\begin{array}{l}\text { High/low } \\
\text { Low/high }\end{array}$ & 197 & 49 & 2.87 & $1.55-5.30$ \\
\hline High/high & 130 & 22 & 1.61 & $0.84-3.45$ \\
\hline
\end{tabular}

fication. To further explore the risk of dementia in this group, we recalculated the Cox analysis for occupational level after including housewives as a third category (ie, high, low, and housewives). Both the low-occupation and housewives groups had increased risk of dementia (RR, 2.25; 95\% CI, 1.32 to 3.84 ; and RR, $2.66 ; 95 \%$ CI, 1.33 to 5.33 , respectively). When the low-occupation and housewives groups were combined, their RR of dementia was 2.32 (95\% CI, 1.37 to 3.91 , which was similar to that of the low-occupation group alone.

Investigation of Assessment Bias.Even though none of the subjects in this analysis were demented at first evaluation, subjects with lower educational or occupational attainment might have performed worse on neuropsychological tests at their initial visit and would have been closer to the dementia cutoff scores. In fact, the frequency of the diagnosis of borderline dementia (CDR, 0.5) at the initial evaluation was higher in the lower educational and occupational groups. Sixty (22.7\%) of the low-education and $29(8.8 \%)$ of the high-education subjects received this diagnosis. Similarly, 64 (19.6\%) of the low-occupation and nine (4.5\%) of the high-occupation subjects received this diagnosis. For subjects in the lower educational and occupational groups, a smaller decline in performance would lead to classification as incident dementia than for those in the higher educational and occupational groups.

We therefore eliminated the $89 \mathrm{sub}$ jects with an initial diagnosis of borderline dementia from the Cox analyses to decrease the possibility that incident dementia was simply a result of small changes in test performance. The findings were essentially unchanged. In the Cox analyses, the RR of incident dementia in the low-education group was 2.40 ( $95 \%$ CI, 1.39 to 4.15 ) and in the lowoccupation group, 2.48 (95\% CI, 1.26 to 4.87). In a Cox model that simultaneously considered the effects of education and occupation and their interaction, the interaction effect was significant $(R R, 2.17$;
$95 \% \mathrm{CI}, 1.40$ to 3.36 ). Analysis of the four separate education/occupation groups was again suggestive of an interaction. In the low-education/low-occupation group the $\mathrm{RR}$ for dementia was 3.50 (95\% CI, 1.64 to 7.47 ); the RR for the high-education/low-occupation group was 1.38 (95\% CI, 0.54 to 3.49 ); and for the low-education/high-occupation group the RR was 1.13 (95\% CI, 0.24 to 5.24 ).

We also examined change in functional capacity as a method of validating whether the diagnosis of dementia was biased in the low-education or low-occupation group. Since change in cognition was the primary determinant of incident dementia, we reasoned that a concomitant change in functional capacity would corroborate the new diagnosis. We therefore examined changes in Blessed Dementia Rating Scale scores from baseline to the follow-up visit using a repeated measure multivariate analysis of variance with the following effects: education (high vs low), incident dementia (no vs yes), and time (baseline vs follow-up) (Figure). The incident dementia effect was significant (F, 95.69; $P<.001$ ); functional capacity was worse in the subjects who became demented. There was also a significant time effect $(\mathrm{F}, 58.1 ; P<.001)$ as well as an incident dementia by time interaction $(F, 9.59$; $P<.002$ ); functional capacity worsened significantly in the incident dementia group only. No other main or interaction effects were significant.

Evaluation of Possible Age Cohort Effects.-We recalculated all Cox analyses stratified by age to account for possible cohort effects. Results were comparable in each case, with only slight was treated as a continuous variable, more years of education was associated with reduced risk of dementia (RR, 0.92 ; $95 \%$ CI, 0.88 to 0.96 ). For education as a dichotomous variable, lower education was associated with a higher RR of incident dementia (RR, 2.04; 95\% CI, 1.35 to 3.10); for low occupation the RR was 2.11 (95\% CI, 1.24 to 3.60 ). When educhanges in $R R$ values. When education
Table 5.-Comparisons of Estimated Cumulative Incidence Rates of Dementia by Age*

\begin{tabular}{|c|c|c|c|}
\hline \multirow[b]{2}{*}{ Group } & \multicolumn{3}{|c|}{$\begin{array}{l}\text { Cumulative Incidence } \\
\text { Rate (SE) by Age, y }\end{array}$} \\
\hline & 75 & 80 & 85 \\
\hline \multicolumn{4}{|l|}{ Education } \\
\hline Low & $\begin{array}{c}0.19 \\
(0.03)\end{array}$ & $\begin{array}{c}0.32 \\
(0.04)\end{array}$ & $\begin{array}{c}0.58 \\
(0.06)\end{array}$ \\
\hline High & $\begin{array}{l}0.09 \\
(0.02)\end{array}$ & $\begin{array}{c}0.18 \\
(0.04)\end{array}$ & $\begin{array}{c}0.28 \\
(0.07)\end{array}$ \\
\hline \multicolumn{4}{|l|}{ Occupation } \\
\hline Low & $\begin{array}{c}0.19 \\
(0.03)\end{array}$ & $\begin{array}{c}0.31 \\
(0.04)\end{array}$ & $\begin{array}{c}0.54 \\
(0.06)\end{array}$ \\
\hline High & $\begin{array}{l}0.04 \\
(0.02)\end{array}$ & $\begin{array}{l}0.15 \\
(0.05)\end{array}$ & $\begin{array}{l}0.38 \\
(0.10)\end{array}$ \\
\hline \multicolumn{4}{|c|}{ Education/occupation } \\
\hline Low/low & $\begin{array}{l}0.22 \\
(0.04)\end{array}$ & $\begin{array}{l}0.36 \\
(0.05)\end{array}$ & $\begin{array}{c}0.60 \\
(0.07)\end{array}$ \\
\hline High/low & $\begin{array}{c}0.15 \\
(0.04)\end{array}$ & $\begin{array}{c}0.21 \\
(0.06)\end{array}$ & $\begin{array}{c}0.41 \\
(0.10)\end{array}$ \\
\hline Low/high & $\begin{array}{l}0.06 \\
(0.06)\end{array}$ & $\begin{array}{l}0.17 \\
(0.11)\end{array}$ & $\begin{array}{l}0.17 \\
(0.11)\end{array}$ \\
\hline High/high & $\begin{array}{c}0.03 \\
(0.02)\end{array}$ & $\begin{array}{l}0.14 \\
(0.05)\end{array}$ & $\begin{array}{c}0.33 \\
(0.12)\end{array}$ \\
\hline
\end{tabular}

*Rates are based on life-table analyses, unadjusted for the covariates. Values in parentheses are standard errors.

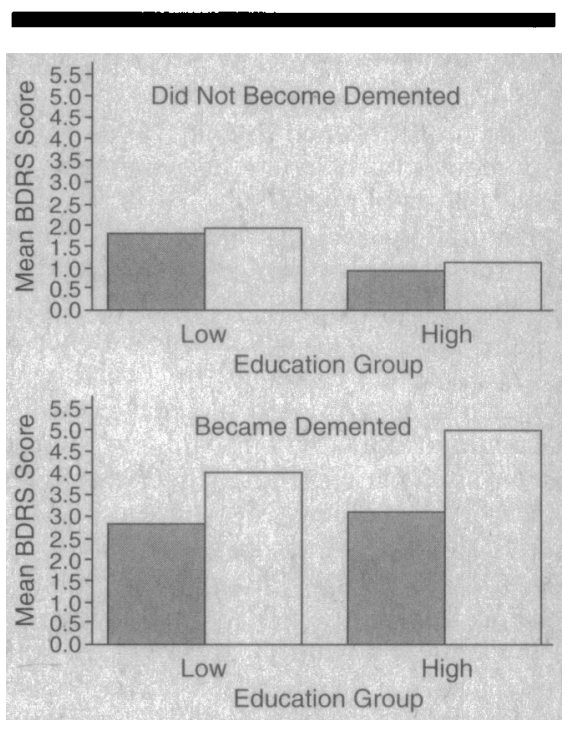

Mean scores on the Blessed Dementia Rating Scale (BDRS) (part I, sections A and B) at baseline (shaded bars) and at follow-up (open bars) for subjects with low ( $<8$ years) and high ( $\geq 8$ years) educational attainment. Higher scores indicate increased difficulty with functional activities of daily living.

cation, occupation, and their interaction were considered simultaneously, the interaction effect was significant (RR, 2.06; $95 \%$ CI, 1.33 to 3.19 ). Analysis of the four separate education/occupation groups was again suggestive of an interaction. In the low-education/low-occupation group the $\mathrm{RR}$ for dementia was 2.65 (95\% CI, 1.43 to 4.94 ); the RR for the high-education/low-occupation group was 1.61 (95\% CI, 0.79 to 3.27); and for the low-education/high-occupation group the RR was 1.32 (95\% CI, 0.43 to 4.09 ).

Evaluation of Evidence for Multiinfarct Dementia.-We used several ap- 
Table 6.-Percentage of Subjects Who Reported Each Atherosclerotic Risk Factor at the First Evaluation*

\begin{tabular}{lcccccc}
$\begin{array}{c}\text { Atherosclerotic } \\
\text { Risk Factor }\end{array}$ & $\begin{array}{c}\text { Low } \\
\text { Education }\end{array}$ & $\begin{array}{c}\text { High } \\
\text { Education }\end{array}$ & $\begin{array}{c}\text { Low } \\
\text { Occupation }\end{array}$ & $\begin{array}{c}\text { High } \\
\text { Occupation }\end{array}$ & $\begin{array}{c}\text { No Incident } \\
\text { Dementia }\end{array}$ & $\begin{array}{c}\text { Incident } \\
\text { Dementia }\end{array}$ \\
\hline Smoking & 39.3 & $47.9 \dagger$ & 45.0 & 48.0 & 45.0 & 40.2 \\
\hline Hypertension & 52.5 & $43.8 \dagger$ & 52.4 & $39.9 \dagger$ & 46.3 & 54.5 \\
\hline Diabetes & 21.2 & $14.1 \dagger$ & 20.5 & $10.0 \dagger$ & 16.2 & 21.9 \\
\hline
\end{tabular}

${ }^{*} x^{2}$ comparisons of the relative frequency of the risk factors were calculated for subjects with low and high educational and occupational attainment and for subjects who did and did not become demented.

$+x^{2}, P<.05$.

proaches to investigate the possibility that our findings could be explained by differences in the contribution of cerebrovascular disease.

We first examined the distribution of stroke-related dementia in the incident dementia cases. Among the 106 incident dementia cases, one subject met our criteria for the diagnosis of stroke-related or multi-infarct dementia and 22 received the diagnosis of possible AD with concomitant stroke. The diagnosis of dementia with stroke was slightly more frequent among the high-education group $(14.5 \%$ of the subjects in the loweducation group and $32.4 \%$ in the higheducation group $\left.\left[\chi^{2}, 4.7 ; P<.05\right]\right)$. There was no difference in the frequency of dementia with stroke between the two occupational groups $(21.1 \%$ of the lowoccupation subjects and $29.4 \%$ of the high-occupation subjects $\left[\chi^{2}, 0.54\right.$; not significant (NS)]).

We next examined the prevalence of preexisting stroke at the initial visit based on history, neurological examination, and scans when available. Fortytwo subjects were identified who had a history or evidence of stroke in the past. A higher frequency of strokes was noted at baseline in the subjects with lower education; $25(9.5 \%)$ of 264 subjects with low education and $17(5.2 \%)$ of 329 subjects with high education had preexisting stroke $\left(\chi^{2}, 4.12 ; P<.05\right)$. Similarly, more subjects in the low-occupation group had evidence of stroke at baseline; $30(9.2 \%)$ of the 327 low-occupation and seven $(4.5 \%)$ of the 201 high-occupation subjects had had strokes $\left(\chi^{2}, 6.19\right.$; $P<.05)$. To evaluate the possible contribution of the presence of preexisting stroke at baseline to the incidence of dementia, we included it as a covariate in the Cox analyses. Results remained virtually unchanged. The $R R$ of incident dementia in the low-education group was 1.98 (95\% CI, 1.31 to 2.99). In the low-occupation group, the RR of incident dementia was 2.21 (95\% CI, 1.29 to 3.77 ). Preexisting stroke was independently associated with an increased $\mathrm{RR}$ of incident dementia in this model (RR, 2.01; 95\% CI, 1.05 to 3.83). In a Cox model that simultaneously considered the effects of education and occupation and their interaction, the interaction effect was significant (RR, 2.17; 95\% CI,
1.40 to 3.36$)$. Stroke was not associated with significantly increased RR of incident dementia in this model. In the analysis of the four separate education/occupation groups, using the high-education/ high-occupation group as the reference, the $R R$ of incident dementia in the low-education/low-occupation group was 2.78 (95\% CI, 1.51 to 5.17); the RR for the high-education/low-occupation group was 1.70 (95\% CI, 0.84 to 3.46), and for the low-education/high-occupation group the RR was 1.36 (95\% CI, 0.44 to 4.18 ). Preexisting stroke was again independently associated with an increased $R R$ of incident dementia in this model (RR, 1.92; $95 \% \mathrm{CI}, 1.01$ to 3.68). There were no significant interactions between educational or occupational attainment and preexisting stroke in any of the models calculated.

Despite these observations, CT or MRI scans were not elicited for this study, and scans for only 83 subjects were available for review. Availability of scans was not related to educational or occupational attainment: scans were available for $12.9 \%$ of the low- and $14.9 \%$ of the higheducation group $\left(\chi^{2}, 0.49 ; \mathrm{NS}\right)$ and for $13.8 \%$ of the subjects with low and $12.4 \%$ of the subjects with high occupational attainment $\left(\chi^{2}, 0.19\right.$; NS). Similarly, availability was unrelated to the four occupation groups: low education/low occupation, $10.7 \%$; high education/low occupation, $18.5 \%$; low education/high occupation 15.8\%; and high education/high occupation, $12.1 \%\left(\chi^{2}, 4.54\right.$; NS). Still, to further address the possibility of increased multi-infarct dementia as in the low-education/low-occupation subjects as an explanation for our findings, we used the three atherosclerotic risk factorshypertension, smoking, and obesity -as markers of possible atherosclerotic disease. The distribution of these risk factors as a function of educational and occupational status and incident dementia is shown in Table 6. More of the subjects in the high- than in the low-education groups had been smokers at some time; diabetes and hypertension were more common in the low-education group. More of the subjects with lower occupational attainment had hypertension and diabetes. The distribution of these risk factors did not differ in subjects who did and did not become demented.
We recalculated all Cox models incorporating the risk factors as covariates to see if they influenced the association of educational and occupational attainment with incident dementia. $\mathrm{Re}-$ sults were essentially unchanged. The $R R$ of incident dementia in the low-education group was 2.12 (95\% CI, 1.35 to $3.34)$; none of the risk factors were associated with significant RRs. In the low-occupation group, the RR of incident dementia was 2.55 (95\% CI, 1.38 to 4.71); hypertension was also associated with an elevated $\mathrm{RR}$ of dementia in this model (RR, 1.71; 95\% CI, 1.07 to 2.74). In a Cox model that simultaneously considered the effects of education and occupation and their interaction, the interaction effect was significant ( $R R, 2.17$; $95 \% \mathrm{CI}, 1.40$ to 3.36 ). In the analysis of the four separate education/occupation groups, using the high-education/highoccupation group as the reference, the $\mathrm{RR}$ of incident dementia in the low-education/low-occupation group was 3.13 (95\% CI, 1.56 to 6.28); the RR for the high-education/low-occupation group was 1.87 (95\% CI, 0.83 to 4.19), and for the low-education/high-occupation group the RR was 1.28 (95\% CI, 0.35 to 4.67 ). Hypertension was again associated with increased $\mathrm{RR}$ of incident dementia in this model (RR, 1.63; 95\% CI, 1.01 to 2.62). There were no significant interactions between educational or occupational attainment and hypertension.

Analysis of Risk Factors in Probable AD vs Other Dementia Diagnoses.-We also calculated the Cox analyses eliminating all incident dementia patients except the 66 patients with the diagnosis of probable AD. Results were comparable to or stronger than those noted when all incident dementia patients were included. Alternately, when subjects with pure AD were eliminated from the analyses and only the other 40 demented patients were included, the $R R$ of incident dementia associated with lower educational or occupational attainment was not significantly increased.

\section{COMMENT}

Our findings suggest that educational and occupational attainment can influence the risk of $\mathrm{AD}$. When these two aspects of life experience were considered simultaneously, the risk of dementia was highest for people with both low education and low occupation.

The concept of a "reserve" that protects against $A D$ must be weighed against the alternate possibility of a detection bias. Standard diagnostic tests may detect dementia more easily in individuals with lower educational or occupational 
attainment, resulting in earlier diagnosis. Katzman ${ }^{8\left(\mathrm{p}^{14)}\right.}$ posed the issue:

The question is whether no or low education enables the clinician to diagnose dementia at an earlier point in time ...., in which case the education effect would confound our diagnostic criteria, or whether the lack of education promotes earlier onset of symptoms ...., constituting a true risk factor for clinical expression of dementia.

He argued that careful application of $D S M-I I I-R$ criteria to dementia reduces the likelihood of a spurious effect of educational level because impairment in more than one cognitive domain and functional impairment are required. In the present study we required evidence of impairment in three cognitive domains as well as functional incapacity. Further, the diagnosis of dementia at follow-up was based on subjects' scores on the same neuropsychological tests that had previously not rated them as demented. Although there is some inherent variability in performance on neuropsychological tests, the performance of a nondemented individual should remain stable for 1 to 3 years.

We also used two approaches to evaluate possible sources of diagnostic bias. Because performance on our tests correlates with educational level, ${ }^{16}$ subjects with lower levels of education or occupation might have performed at levels closer to dementia cutoff scores at first evaluation. They would later be diagnosed with dementia after smaller declines in performance than those of subjects with higher educational or occupational attainment. We therefore eliminated subjects with scores indicating borderline dementia (CDR, 0.5). This ensured that incident dementia was not simply a function of some small (and perhaps chance) variation in test scores and required a more substantial change in performance for the diagnosis of dementia. Analyses with this trimmed set of patients replicated the findings in the complete cohort.

We also evaluated the validity of the dementia diagnoses by investigating functional decline. Although evidence of social or occupational dysfunction was also required, no formal cut points were established for the functional measures, and diagnosis relied heavily on neuropsychological tests. The functional measures are therefore relatively independent validators of dementia. Functional scores in the newly demented patients from both high and low educational groups declined significantly from baseline values.

These results imply that higher incidence of dementia in the low-education/ low-occupation group is not simply a result of detection bias, but that possi- bility still remains. It may have been more difficult to detect dementia in subjects with high education or occupation because of the sensitivity of the neuropsychological tests. However, to the extent that the diagnosis of dementia corresponds to changes in performance that disrupt daily activities, the concept of detection bias complements that of reserve.

We addressed in several ways the possibility that the association of education and occupation with incident dementia might be due to increased multiinfarct dementia in lower educational and occupational groups. Of the subjects who became demented, a higher proportion of the high-education subjects received a diagnosis of strokerelated dementia or possible $\mathrm{AD}$ with concomitant stroke, suggesting that higher incidence of dementia in the loweducation group was not stroke related. The frequency of dementia with stroke did not differ as a function of occupational attainment.

We investigated the frequency of preexisting strokes at the initial visit and found that they were more common in the groups with lower education and occupation. Cox analyses that controlled for the presence of stroke at baseline still demonstrated the increased RR of incident dementia associated with lower educational and occupational attainment. The presence of stroke was independently associated with increased RR of incident dementia in most models, but there was interaction between stroke and educational or occupational attainment. When the subjects with preexisting stroke were eliminated from the Cox analyses, the relationship between loweducation/low-occupation and incident dementia was unchanged.

While CT or MRI scans were not available for all subjects, the availability of the scans did not differ as a function of education or occupation. Still, it is possible that we did not detect cerebrovascular disease in some subjects. We therefore used atherosclerotic risk factors as markers of possible atherosclerotic disease. In Cox models that controlled for these risk factors, the $R R$ of incident dementia associated with education and occupation was unchanged. Also, there was no interaction between the risk factors and education or occupation. The presence of hypertension was weakly but independently associated with incident dementia. The role of cardiovascular disease in late-onset dementia remains controversial. ${ }^{37,38}$ Nonetheless, our analyses indicate no relationship between the effects of low education/low occupation and hyptertension, suggesting that they are independent.
In sum, none of our analyses support the possibility that increased incidence of dementia in the low educational or occupational groups was a function of differential risk for stroke-related dementia.

Overall, the incident rate of dementia in our cohort was 86.7 per 1000 personyears, which is quite high relative to other reports. This may in part be related to the techniques used to acquire subjects. A high proportion of our subjects were recruited from sources that would be more likely to serve individuals at higher risk for dementia. The observed incidence of dementia herein most likely represents the characteristics of a high-risk sample. We cannot definitively exclude the possibility that the recruitment process in some way influenced the observed effects of education and occupation. However, we have no evidence of differential participation or follow-up rates based on educational or occupational attainment. Also, the design of the incidence study and supplementary analyses ensures that our observations are not simply the result of diagnostic bias.

Although it may appear unlikely that aspects of life experience could impede the development of the pathological changes of AD, Friedland ${ }^{7}$ suggested that cerebral activation from life experience might interfere with the physiological events that interact to cause AD. Alternatively, life experiences may not be risk factors in and of themselves but may be related to some unknown causal factor. Education and occupation might then be surrogate markers for the actual risk factor.

Advanced educational and occupational attainment may also supply a reserve that allows an individual to cope longer before $\mathrm{AD}$ is clinically expressed. This reserve could be an acquired set of skills or repertoires ${ }^{9,12,13}$ or could be the result of increased synaptic density in neocortical association cortex acquired on the basis of stimulation. ${ }^{8}$ Our data are consistent with a reserve hypothesis. Education and occupation may simply measure potential present at birth. This possibility would not have a differential effect on our findings. However, low education and occupation made additive contributions to the risk of dementia, supporting the concept that reserve is modulated by different aspects of life experience.

The reserve hypothesis would also predict that in patients with similar clinical severity, AD pathology would be more severe in those with more education. We have tested this prediction in a separate set of studies of patients with established diagnosis of AD. Using xe- 
non regional cerebral blood flow, we assessed perfusion in the parietotemporal area as an index of AD pathology because both regional cerebral blood flow $^{39}$ and positron emission tomography studies ${ }^{40}$ have implied a characteristic impairment of parietotemporal perfusion and metabolism that is relatively specific for $A D$, correlates with disease severity, and is homologous with areas of AD histopathology. In patients with comparable clinical severity of dementia, increasing years of education was related to decreased parietotemporal perfusion, supporting our hypotheses. ${ }^{12}$ In a later study, we incorporated information about the patients' primary lifetime occupations. ${ }^{13}$ After controlling for age and clinical se-

\section{References}

1. Zhang MY, Katzman R, Jin H, et al. The prevalence of dementia and Alzheimer's disease (AD) in Shanghai, China: impact of age, gender and education. Ann Neurol. 1990:27:428-437.

2. Dartigues JF, Gagnon M, Miche P, et al. Le programme de recherche paquid sur l'epidémiologie de la démence méthodes et résultats initialix. Rev Neurol (Paris). 1991;147:225-230.

3. Bonaiuto S, Rocea WA, Lippi A, et al. Impact of education and occupation on prevalence of Alzheimer's disease (AD) and multi-infaret dementia (MID) in Appignano, Macerata Province, Italy. Neurology. 1990;40(suppl 1):346. Abstract.

4. Fratiglioni L, Grut M, Forsell Y, et al. Prevalence of Alzheimer's disease and other dementias in an elderly urban population: relationship with age, sex and education. Neurology. 1991;41:1886-1892. 5. Sulkava R, Wikström J, Aromaa, et al. Prevalence of severe dementia in Finland. Neurology. 1985;35:1025-1029.

6. Korczyn AD, Kahana E, Galper Y. Epidemiology of dementia in Ashkelon, Israel. Neuroepidemiology. 1991;10:100. Abstract.

7. Friedland R. Epidemiology, education, and the ecology of Alzheimer's disease. Neurology. 1993; 43:262-249.

8. Katzman R. Education and the prevalence of dementia and Alzheimer's disease. Neurology. 1993; 43:13-20.

9. Mortimer JA. Do psychosocial risk factors contribute to Alzheimer's disease? In: Henderson AS, Henderson JH, eds. Etiology of Dementia of Alzheimer's Type. New York, NY: John Wiley \& Sons Inc; 1988:39-52.

10. Gurland BJ. The borderlands of dementia: the influence of sociocultural characteristics on rates of dementia occurring in the senium. Aging. 1981;15: 61-84.

11. Satz P. Brain reserve capacity on symptom onset after brain injury: a formulation and review of evidence for threshold theory. Neuropsychology. 1993;7:273-295.

12. Stern Y, Alexander GE, Prohovnik I, Mayeux $R$. Inverse relationship between education and parietotemporal perfusion deficit in Alzheimer's disease. Ann Neurol. 1992;32:371-375.

13. Stern Y, Stricks L, Alexander G, Prohovnik I, Mayeux R. Relationship between occupational demands and parietotemporal perfusion in Alzheimer's verity of dementia, parietotemporal perfusion showed significant correlations with occupational indexes. We concluded that occupational demands, similar to but independent of education, may provide a reserve that delays the clinical expression of AD.

Factors other than educational and occupational attainment could also contribute to this reserve. For example, certain leisure activities might provide intellectual activity or stimulation. We focused on education and occupation in these analyses because they were readily and accurately measured and obtained, but we plan to address other potential contributors in future studies.

The fact that our findings were seen most clearly when only the incidence of

disease. Ann Neurol. 1992;32:270. Abstract.

14. Kittner SJ, White LR, Farmer ME, et al. Methodological issues in screening for dementia: the problem of education adjustment. J Chronic Dis. 1986; 39:163-170.

15. Beard CM, Kokmen E, Offord K, Kurland LT. Lack of association between Alzheimer's disease and education, occupation, marital status, or living arrangement. Neurology. 1992;42:2063-2068.

16. Stern Y, Andrews H, Pittman J, et al. Diagnosis of dementia in a heterogeneous population development of a neuropsychological paradigmbased diagnosis of dementia and quantified correction for the effects of education. Arch Neurol. 1992; 49:453-460.

17. Buschke H, Fuld PA. Evaluating storage, retention, and retrieval in disordered memory and learning. Neurology. 1974;24:1019-1025.

18. Benton AL. The Visual Retention Test. New York, NY: The Psychological Corp; 1955.

19. Wechsler D. Wechsler Adult Intelligence Scale-Revised. New York, NY: The Psychological Corp; 1981.

20. Mattis S. Mental status examination for organic mental syndrome in the elderly patient. In: Bellak L, Karasu TB, eds. Geriatric Psychiatry. New York, NY: Grune \& Stratton; 1976.

21. Kaplan E, Goodglass H. Weintraub S. Boston Naming Test. Philadelphia, Pa: Lea \& Febiger; 1983.

22. Benton AL, Hamsher KD. Multilingual Aphasia Examination. Iowa City: University of Iowa; 1976. Manual, revised in 1978.

23. Goodglass H, Kaplan D. The Assessment of Aphasia and Related Disorders. 2nd ed. Philadelphia, Pa: Lea \& Febiger; 1983.

24. The Rosen Drawing Test. Bronx, NY: Veterans Administration Medical Center; 1981.

25. Katzman R, Brown T, Fuld P. Validation of a short orientation-memory-concentration test of cognitive impairment. Am J Psychiatry. 1983;140:734738.

26. Blessed G, Tomlinson BE, Roth M. The association between quantitative measures of dementia and of senile changes in the cerebral grey matter of elderly subjects. Br J Psychol. 1968;225:797-811.

27. Schwab JF, England AC. Projection technique for evaluating surgery in Parkinson's disease. In: Gillinghan FS, Donaldson MN, eds. Third Sympo- pure $\mathrm{AD}$ was considered strengthens the concept of cognitive reserve. In other forms of dementia, such as possible $\mathrm{AD}$ or stroke-related dementia, the concept of cognitive reserve might be difficult to document because of the other pathological processes at work.

In summary, the present findings are consistent with the hypothesis that higher lifetime educational and occupational attainment can influence the incidence of $\mathrm{AD}$, either by reducing ease of detection or by providing a reserve against the early manifestation of $\mathrm{AD}$.

This study was supported by federal grants AG07232, AG07370, NS26179, and RR00645 and by The Charles S. Robertson Memorial Gift for Alzheimer's Disease from the Banbury Fund.

sium on Parkinson's Disease. Edinburgh, Scotland: E \& S Livingstone; 1969:152-157.

28. Spitzer RL, Williams JBW. Structured Clinical Interview for DSM III-R-Hamilton Version. New York: New York State Psychiatric Institute; 1986. 29. Hamilton M. A rating scale for depression. J Neurol Neurosurg Psychiatry. 1960;23:56-62 30. Williams JBW. A structured interview guide for the Hamilton Depression Rating Scale. Arch Gen Psychiatry. 1988;45:742-747.

31. American Psychiatric Association, Committee on Nomenclature and Statistics. Diagnostic and Statistical Manual of Mental Disorders, Revised Third Edition. Washington, DC: American Psychiatric Association; 1987.

32. MeKhann G, Drachman D, Folstein M, et al. Clinical diagnosis of Alzheimer's disease: report of the NINCDS-ADRDA Work Group under the auspices of the Department of Health and Human Services Task force on Alzheimer's disease. Neurology. 1984;34:939-944.

33. Hughes CP, Berg L, Danziger WL, et al. A new clinical scale for the staging of dementia. $B r J P s y$ chiatry. 1982;146:566-572.

34. Lawless JF. Statistical Model and Methods for Lifetime Data. New York, NY: John Wiley \& Sons Ine; 1982.

35. Kaplan EL, Meier P. Nonparametric estimation from incomplete observations. $J$ Am Stat Assoc. 1958;53:457-481.

36. Rothman KJ. Modern Epidemiology. Boston, Mass: Little Brown \& Co; 1986:311-326.

37. Aronson MK, Ooi WL, Morgenstern $\mathrm{H}$, et al. Women, myocardial infarction, and dementia in the very old. Neurology. 1990;40:1102-1106.

38. Zimetbaum P, Frishman W, Aronson M. Lipids, vascular disease and dementia with advancing age: epidemiologic considerations. Arch Intern Med. 1991;151:240-244.

39. Risberg J, Gustafson L. Regional cerebral blood flow in psychiatric disorders. In: Knezevic S, Maximilian V, Mubrin Z, Prohovnik I, Wade J, eds. Handbook of Regional Cerebral Blood Flow. Hillsdale, NJ: Erlbaum; 1988:219-240.

40. Friedland RP, Brun A, Bundinger TF. Pathological and positron emission tomographic correlations in Alzheimer's disease. Lancet. 1985;1:228. 